\title{
MYOCARDIAL FIBROSIS AND CALCAREOUS EMBOLI IN VALVULAR HEART DISEASE
}

\author{
BY \\ E. D. WIGLE* \\ From the Department of Pathology, Postgraduate Medical School, London \\ Received March 3, 1957
}

In the past decade the great advances of cardiac surgery have focused new attention on aortic and mitral valve disease. The investigation of these cases by clinical and technical means has been the subject of increased interest (Wood, 1954; Gorlin et al., 1955). Study of the pathology of the mitral and aortic valves has correspondingly increased (Brock, 1952). The observation that myocardial fibrosis is unduly frequent and occasionally extensive in cases of congenital and acquired aortic stenosis with little or no coronary artery disease has often been made (Friedberg, 1949; Marquis and Long, 1955). The occurrence of angina pectoris, the electrocardiographic changes on exercise and the liability to sudden death in these cases have led these authors and others to suggest that the myocardial fibrosis is due to myocardial ischæmia as a result of functional coronary insufficiency. In addition, in cases of mitral stenosis, the occurrence of angina pectoris and the cardiographic changes on exercise have been attributed to myocardial ischæmia as a result of functional coronary insufficiency (Wood; Stuckey, 1955). In an attempt to determine how much myocardial fibrosis that is, not attributable to coronary disease or to rheumatic myocarditis, and therefore possibly due to functional coronary insufficiency, may occur in these two groups, seven cases of aortic stenosis and seven cases of mitral stenosis (with and without regurgitation) were studied post mortem by a method combining a coronary artery injection technique with careful examination of the myocardium. The necropsy findings of a large number of cases of both aortic and mitral stenosis were also reviewed. The amount of myocardial fibrosis noted in the two groups together with the finding of previously undescribed arterial lesions prompt this report of the results.

\section{METHOD}

At necropsy the hearts were carefully dissected, cleared of any clots, and weighed. Shortly thereafter (usually within three hours), the coronary arteries were cannulated under water at $37^{\circ} \mathrm{C}$. and perfused with water of the same temperature until the washings returned clear from the coronary sinus. Approximately $100 \mathrm{ml}$. of 15 per cent formol-calcium were then injected in order to fix the musculature, followed by 10 to $20 \mathrm{ml}$. of warm water (to prevent mixing of the formol-calcium and the barium gelatine). Warmed barium-gelatine, prepared according to the technique of Gross (1921), was then injected into the arteries at a pressure of $140 \mathrm{~mm}$. $\mathrm{Hg}$. The heart was placed in iced water until the gelatine had set, and an X-ray was taken. Following this the heart was placed in a solution of 15 per cent formol-calcium for further fixation for at least one week. Dissection of the heart was then carried out. Using the radiograph as a guide the coronary arteries were sectioned at 3-4 mm. intervals in order to extend, by gross and microscopic examination, the X-ray findings. The heart muscle was then sliced from apex to base at $5-\mathrm{mm}$. intervals and the slices examined under a magnifying lens. The position, appearance, and size of any myocardial lesion were recorded, blocks being taken from the abnormal areas for microscopic examination. In addition blocks were taken

* During the tenure of a British Council Scholarship. Present address : Toronto General Hospital, Toronto, Ontario, Canada. 
from muscle of normal appearance from the postero-basal and antero-apical regions of the left and right ventricles.

\section{INTERPRETATION}

Coronary Atheroma. In the dissection of the coronary arteries some areas of atheroma were found that had failed to cause coronary narrowing in the radiographs of the injected hearts. Such atheromatous areas were at times seen to narrow the lumina of vessels by up to one-quarter of their diameters when compared with adjacent portions of the same vessels, but at other times did not cause any narrowing of the vessel lumina at all. It has been noted previously that atheroma does not necessarily cause coronary narrowing (Stewart et al., 1935). As a result of the above findings it has been found convenient to grade coronary artery disease in the following manner.

Grade I: No coronary narrowing either on dissection or in the radiograph.

Grade II: Narrowing up to one-quarter of the diameter of the vessel lumen on dissection, but no radiographic evidence of coronary narrowing.

Grade III: Narrowing of between one-quarter and one-half of the diameter of the vessel lumen on dissection, associated with coronary narrowing in the radiograph.

Grade IV: Narrowing of greater than one-half of the diameter of the vessel lumen on dissection or in the radiograph.

Grade V: Complete obstruction of the vessel lumen.

No occluding coronary thrombus was found.

In Tables I and II the grade of atheroma recorded represents the most severe degree of atheroma found in any of the coronary arteries of that case. In the six cases with Grade I coronary atheroma there were at most two intimal collections of cholesterol. For the purposes of the description and discussion that follow the coronary arteries of this group are considered as having normal lumina.

Size of Coronary Arteries. At every examination the three major coronary arteries (left anterior descending, left circumflex, and right) were measured near their origins. From their diameters their total cross-sectional areas were calculated (Table I and II) and plotted against the weight of the heart.

TABLE I

Coronary Atheroma and Myocardial Fibrosis in Seven Cases of Mitral Stenosis with or without INCOMPETENCE

\begin{tabular}{|c|c|c|c|c|c|c|c|c|c|c|c|}
\hline \multirow{2}{*}{$\begin{array}{l}\text { Case } \\
\text { No. }\end{array}$} & \multirow{2}{*}{ Age } & \multirow{2}{*}{ Sex } & \multirow{2}{*}{$\begin{array}{l}\text { Valve } \\
\text { lesion }\end{array}$} & \multirow{2}{*}{$\begin{array}{l}\text { Valve circ. } \\
\text { (mm.) }\end{array}$} & \multirow{2}{*}{$\begin{array}{l}\text { Heart } \\
\text { wt. }\end{array}$} & \multirow{2}{*}{$\begin{array}{l}\text { Total coronary } \\
\text { bore (sq. } \mathrm{mm} \text {.) }\end{array}$} & \multirow{2}{*}{$\begin{array}{l}\text { Coronary } \\
\text { atheroma }\end{array}$} & \multicolumn{4}{|c|}{ Macroscopic fibrosis } \\
\hline & & & & & & & & M.I. & I.F. & L.F.F.S. & S.F.F.S. \\
\hline 1 & 63 & F & M.S. $†$ & 60 & 480 & $45 \cdot 0$ & IV & 1 & 0 & $\mathbf{0}$ & 0 \\
\hline 2 & 39 & F & M.S. & 55 & 310 & $34 \cdot 8$ & I & 0 & 0 & $\mathbf{0}$ & 3 \\
\hline 3 & 32 & $\mathbf{M}$ & M.S. & 40 & 456 & $44 \cdot 8$ & I & 0 & $\mathbf{0}$ & $\mathbf{0}$ & $\mathbf{0}$ \\
\hline 4 & 52 & $\mathbf{F}$ & M.S. & 35 & 338 & $38 \cdot 0$ & $0^{*}$ & 0 & 0 & 0 & 5 \\
\hline 5 & 55 & $\mathbf{F}$ & $\begin{array}{l}\text { M.S. } \\
\text { M.R. } \ddagger\end{array}$ & 50 & 527 & $63 \cdot 7$ & II & 0 & 0 & 0 & 3 \\
\hline 6 & 56 & F & $\begin{array}{l}\text { M.S. } \\
\text { M.R. }\end{array}$ & 60 & 495 & $32 \cdot 0$ & 0 & 0 & 0 & 0 & 2 \\
\hline 7 & 57 & $\mathbf{M}$ & $\begin{array}{l}\text { M.S. } \\
\text { M.R. }\end{array}$ & 50 & 615 & $63 \cdot 0$ & II & 1 & 0 & 0 & 2 \\
\hline
\end{tabular}

* See text.

+ Mitral stenosis.

$\ddagger$ Mitral regurgitation.
M.I. = myocardial infarct.

I.F. = interstitial fibrosis.

L.F.F.S. = large focal fibrous scar.

S.F.F.S. = small focal fibrous scar. 
TABLE II

Coronary Atheroma and Myocardial Fibrosis in Seven Cases of Aortic Stenosis, with or without INCOMPETENCE

\begin{tabular}{|c|c|c|c|c|c|c|c|c|c|c|}
\hline \multirow{2}{*}{$\begin{array}{l}\text { Case } \\
\text { No. }\end{array}$} & \multirow{2}{*}{ Age } & \multirow{2}{*}{ Sex } & \multirow{2}{*}{$\begin{array}{l}\text { Degree of aortic } \\
\text { stenosis }\end{array}$} & \multirow{2}{*}{$\begin{array}{l}\text { Heart } \\
\text { wt. }\end{array}$} & \multirow{2}{*}{$\begin{array}{l}\text { Total coronary } \\
\text { bore (sq. } \mathrm{mm} \text {.) }\end{array}$} & \multirow{2}{*}{$\begin{array}{l}\text { Coronary } \\
\text { atheroma* }\end{array}$} & \multicolumn{4}{|c|}{ Macroscopic fibrosis } \\
\hline & & & & & & & M.I. & I.F. & L.F.F.S. & S.F.F.S. \\
\hline 8 & 40 & $\mathbf{M}$ & Severe & 865 & $70 \cdot 7$ & I & 1 & + & 2 & 14 \\
\hline 9 & 48 & $\mathbf{F}$ & $\begin{array}{l}\text { Severe } \\
+ \text { A.I. } \dagger\end{array}$ & 763 & $52 \cdot 5$ & I & 0 & ++ & 4 & 11 \\
\hline 10 & 61 & $\mathbf{M}$ & Severe & 699 & $68 \cdot 0$ & I & 1 & +++ & 2 & 3 \\
\hline 11 & 75 & $\mathbf{M}$ & Moderate & 290 & $38 \cdot 9$ & I & 0 & 0 & 0 & 13 \\
\hline 12 & 56 & $\mathbf{M}$ & $\begin{array}{l}\text { Moderate } \\
\text { +A.I. }\end{array}$ & 790 & $68 \cdot 0$ & III & 1 & + & 2 & 2 \\
\hline 13 & 78 & $\mathbf{M}$ & Mild & 497 & $60 \cdot 7$ & V & 1 & ++ & 3 & 3 \\
\hline 14 & 65 & $\mathbf{F}$ & Mild & 499 & $45 \cdot 1$ & 0 & 0 & 0 & 0 & 0 \\
\hline
\end{tabular}

* See text.

$\uparrow$ Aortic incompetence.
M.I. = myocardial infarct.

I.F. = interstitial fibrosis.

L.F.F.S. = large focal fibrous scar.

S.F.F.S. = small focal fibrous scar.

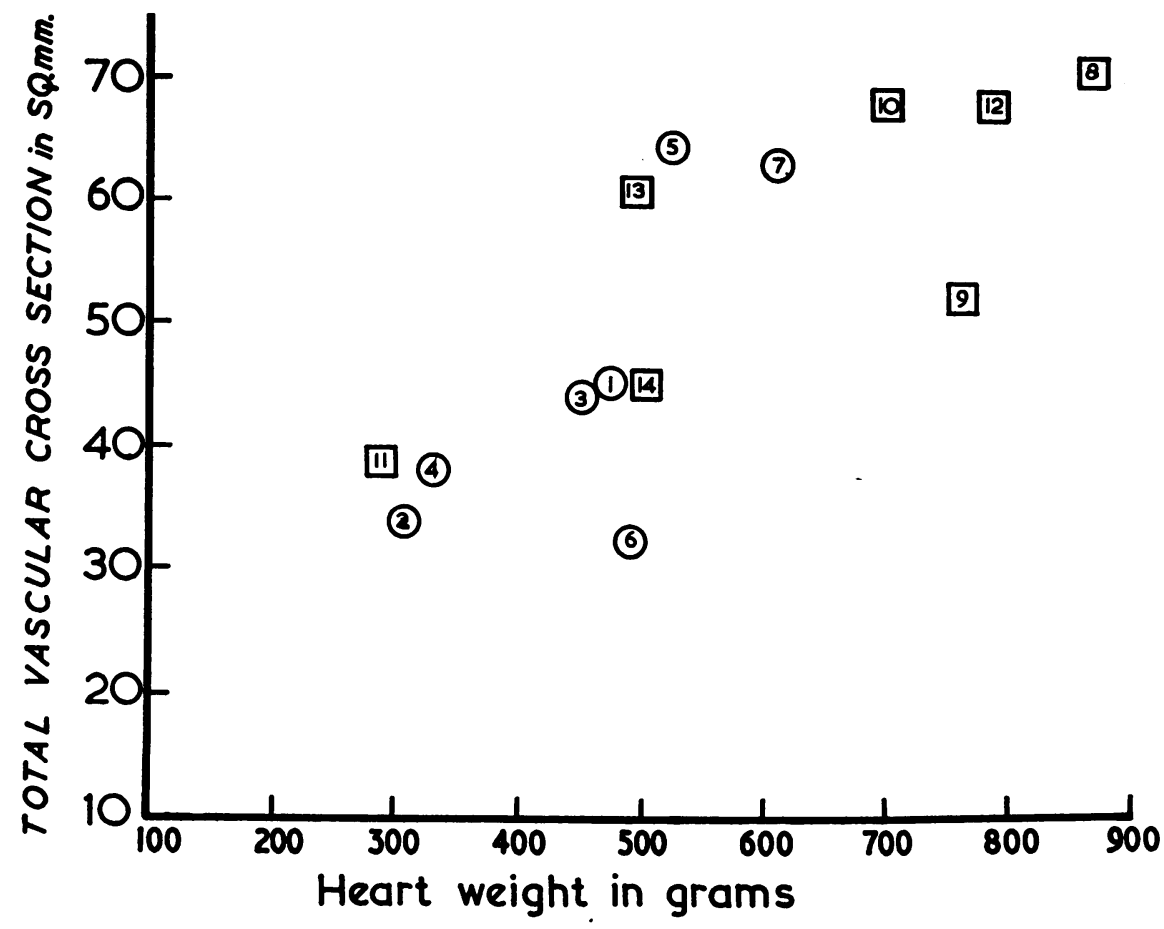

FIG. 1.-Graph illustrating the linear relationship between the heart weight and total cross-section of the main coronary vessels. Numbers 1 to 7 (in circles) are the cases of mitral stenosis; numbers 8 to 14 (in squares) are the cases of aortic stenosis. 
The resulting graph (Fig. 1) showed a fairly close scatter along a straight line and indicates that there is a direct relationship between the size of the coronary arteries and the heart weight.

Myocardial Lesions. For the sake of clarity, macroscopic myocardial fibrosis has been described in arbitrarily chosen terms. The term old myocardial infarct refers to an area of solid fibrous tissue greater than $20 \mathrm{~mm}$. in maximum dimension. Interstitial fibrosis refers to an area of streaky myocardial fibrosis of variable size. A focal fibrous scar refers to an area of solid fibrous tissue not greater than $20 \mathrm{~mm}$. in maximum dimension. This type of lesion has been further divided into small focal fibrous scars $(5 \mathrm{~mm}$. or less in maximum dimension) and large focal fibrous scars (varying in size between $6 \mathrm{~mm}$. and $20 \mathrm{~mm}$. in maximum dimension).

Assessment of the degree of microscopic myocardial fibrosis was made on the blocks taken of muscle that appeared normal macroscopically. Here the term replacement fibrosis refers to areas of fibrous tissue replacing muscle cells. This is to be distinguished from the reticular fibrosis that is seen in chronic myocardial hypertrophy (Harrison and Wood, 1949). No attempt was made to distinguish rheumatic from ischæmic myocardial fibrosis.

Recent myocardial infarcts were not noted but areas of recent muscle necrosis were. These varied greatly in size, some being visible macroscopically, others only microscopically. They were characterized by necrosis and disappearance of muscle cells, preservation of the stroma, and some mononuclear cell infiltration. The end result was myocardial fibrosis due to fibrous tissue proliferation and/or stromal collapse (Fig. 5).

The descriptions below refer only to abnormalities seen in the left ventricular muscle since no significant changes were noted in the right ventricles.

\section{RESULTS}

Mitral Stenosis. Four cases of mitral stenosis (Cases 1, 2, 3 and 4) and three cases of mitral stenosis and regurgitation (Cases 5, 6 and 7) were studied. There was no history of angina pectoris in any of the seven cases. The pathological findings are summarized in Table I. The myocardial infarct found in Case 1 could be accounted for on the basis of coronary artery disease. In Case 7 , however, there was only Grade II atheroma of the left circumflex coronary artery and yet there was a large postero-basal myocardial infarct. There were no old myocardial infarcts in the other five cases. No areas of interstitial fibrosis or any large focal fibrous scars were noted in any of the seven cases. Five of the seven cases had small focal fibrous scars, the majority of these being situated in the posterior wall of the left ventricle. In Case 5 the three small focal fibrous scars were probably due to myocardial ischæmia resulting from an embolus described below. Of the remaining four cases with small focal scars, only in Case 4 (with the most severe degree of mitral stenosis) were these scars larger than $2 \mathrm{~mm}$. in maximum dimension and in this case there were five scars measuring between $3 \mathrm{~mm}$. and $5 \mathrm{~mm}$. in maximum dimension. Also in Case 4, although there was no evidence of coronary atheroma, five recent mural thrombi (approximately 2-3 days old) were found in small coronary arteries (varying from $0.75 \mathrm{~mm}$. to $2 \mathrm{~mm}$. in diameter). None of these thrombi completely occluded a vessel but in areas of myocardium supplied by the affected vessels, microscopic areas of recent muscle necrosis measuring about $1 \mathrm{~mm}$. in maximum dimension were found. Recent myocardial damage was not noted in the other six cases. Microscopic examination of normal appearing blocks of myocardium in all of the seven cases revealed at most only slight fibrosis.

Case 5 is of particular interest in that a piece of calcium was noted in the dissection to be lodged at the bifurcation of the right coronary artery posteriorly. Microscopic section of this (Fig. 2) showed an essentially normal vessel within which was a mass of calcareous material identical in appearance with the calcareous deposits on the mitral valve which had been split at operation one year before the patient's death. This mass in the lumen of the vessel is believed to be an embolus that originated from the mitral valve at the time of valvotomy or shortly thereafter. In the area of myocardium supplied by the right coronary artery there were three small focal fibrous scars. Mitral valvotomy had also been performed on Cases 2, 3, and 7; in Cases 2 and 3 the valves were not calcified and in Case 7 the valve was calcified but no coronary emboli were found. 


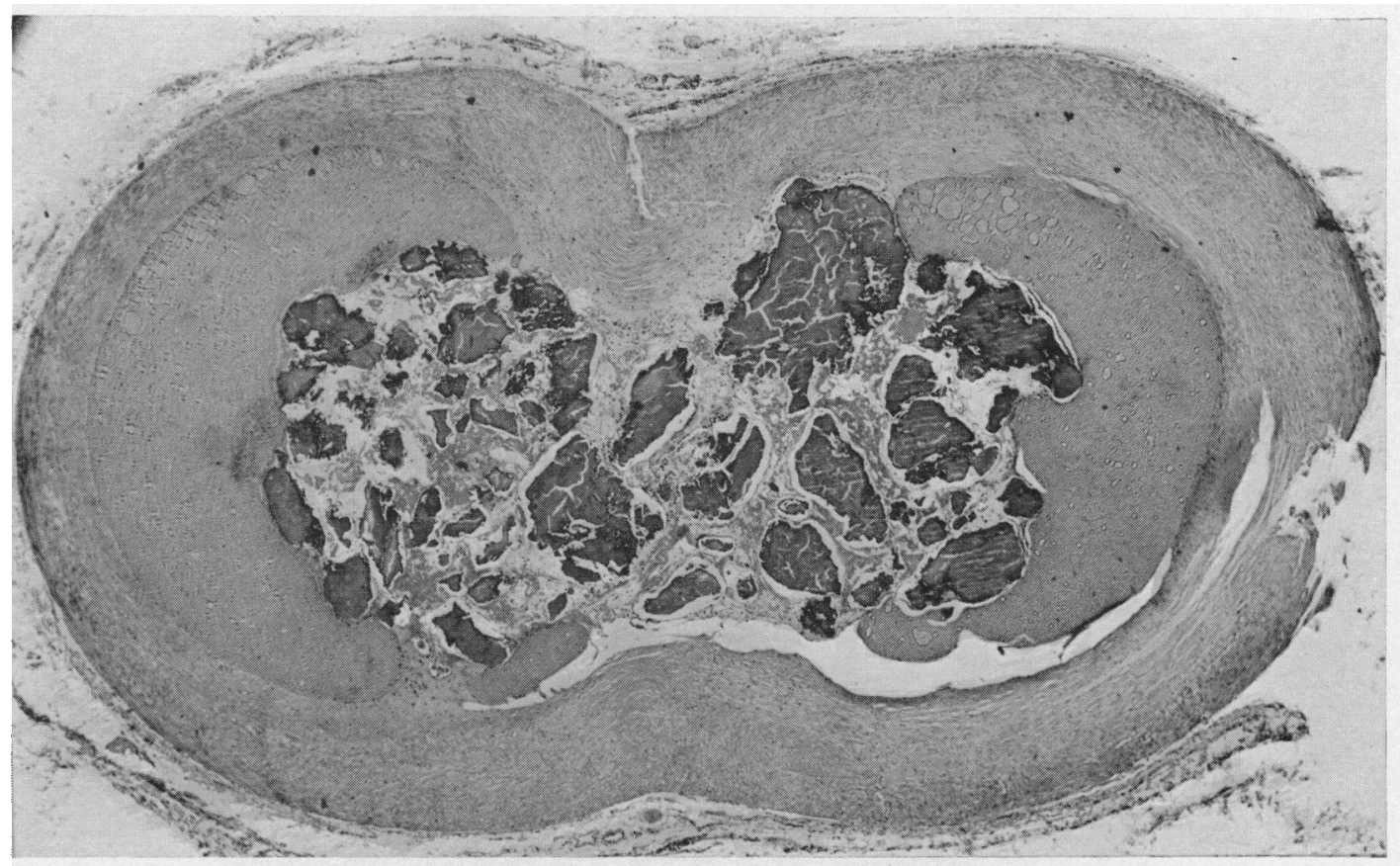

FIG. 2.-Calcareous embolus lodged at the bifurcation of the right coronary artery in Case 5. Mitral valvotomy on a heavily calcified valve was performed one year prior to death and this embolus is believed to have originated from the valve at that time. It is firmly attached to the vessel wall by fibrous tissue. Barium gelatine injection fills the part of the lumen not occupied by the embolus. $(\times 30)$.

Aortic Stenosis. The pathological findings in the seven cases of aortic stenosis studied are summarized in Table II. In Cases 9 and 14 calcific aortic stenosis was believed to have developed on congenital bicuspid aortic valves; in the remaining five cases the aortic stenosis was believed to be rheumatic in origin. The degree of stenosis of the aortic valve was graded mild, moderate, or severe according to whether the valve admitted the index finger, only the tip of the index finger, or less than the tip (Kumpe and Bean, 1948). Of the seven cases studied three had severe aortic stenosis, two moderate, and two mild. Cases 9 and 12 had significant aortic regurgitation in addition. Case 14 was the only one in which angina pectoris was noted, and this symptom disappeared with the correction of a severe anæmia. The three cases of severe aortic stenosis and Case 12 with moderate aortic stenosis had 18- to 24-month histories of congestive cardiac failure and grossly enlarged hearts.

The myocardial fibrosis in Case 13 (mild aortic stenosis) could be accounted for on the basis of severe coronary artery disease (Grades IV and V). In Case 12 (moderate aortic stenosis plus regurgitation) although there was Grade III atheroma of the right coronary artery and Grade II atheroma of the other major coronary vessels, the amount of myocardial fibrosis found was considered quite in excess of that to be expected from the degree of coronary artery disease present. The coronary lumina of the remaing five cases of aortic stenosis were normal (Cases 8, 9, 10 and 11 having Grade I atheroma and Case 14 had no coronary atheroma). Case 14 (mild aortic stenosis) had no macroscopic myocardial fibrosis, and Case 11 (moderate aortic stenosis) had thirteen small focal fibrous scars. Cases 8, 9 and 10 (severe aortic stenosis) had severe myocardial fibrosis, including old infarcts, interstitial fibrosis, and large and small focal fibrous scars. Microscopic examination of normal appearing blocks of muscle from these three cases revealed moderate to severe amounts of replacement fibrosis predominantly in the subendocardinal region of the left ventricle. There was reticular fibrosis throughout the left ventricle of each of these three cases. 


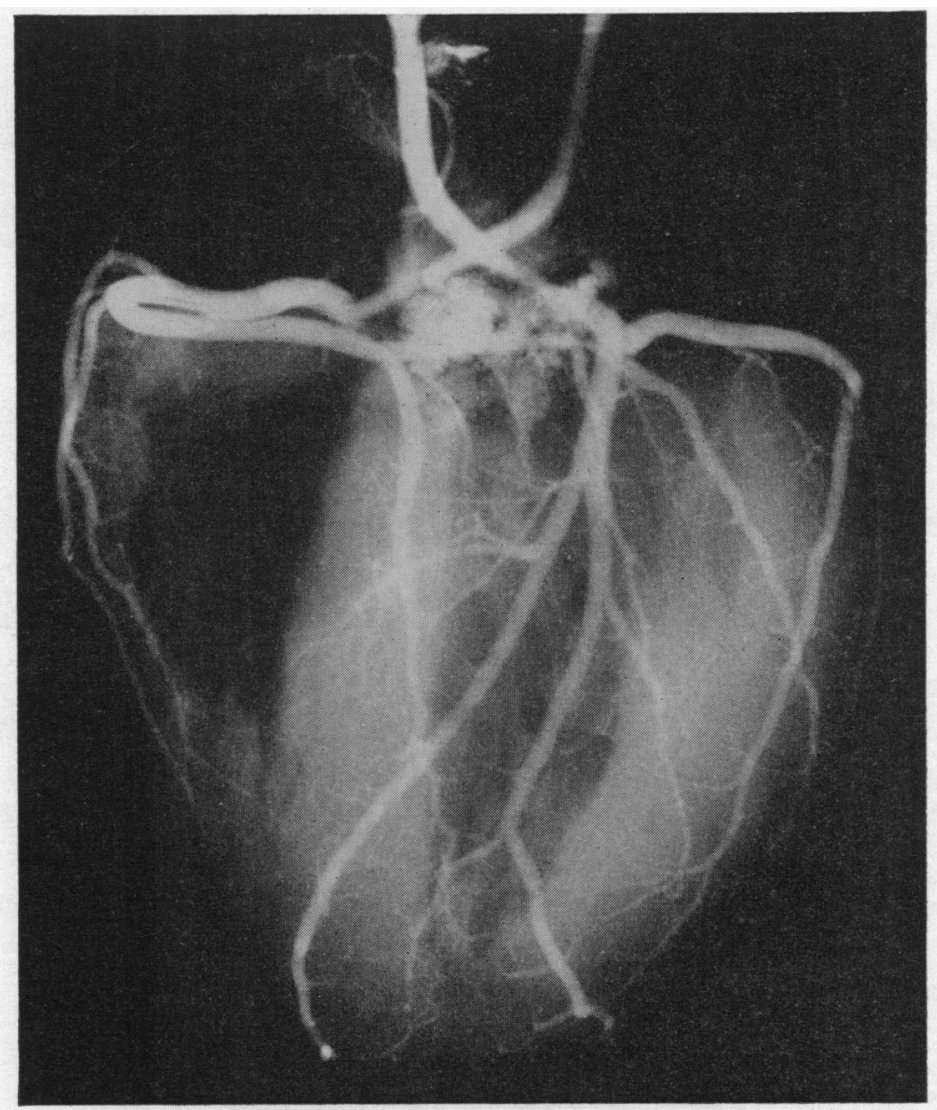

Fig. 3.-Aortic stenosis (Case 8), showing X-ray of injected heart. The vessels are enlarged and smooth bored in appearance. Note the heavily calcified aortic valve.

The radiograph of the injected heart in Case 8 is shown in Fig. 3. In spite of this seemingly adequate coronary arterial tree, in addition to the macroscopically visible myocardial fibrosis, there was an area in the outer quarter of the lateral wall measuring $2 \times 1 \times 1 \mathrm{~cm}$., throughout which confluent patches of recent muscle necrosis were seen (Fig. 4 and 5). Cases 9 and 10 showed microscopic areas of recent muscle necrosis in the subendocardial region of the left ventricle. In all the cases of aortic stenosis the various types of macroscopic fibrosis were greatest in the mid-portion of the left ventricular wall and least so in the subepicardial region. The postero-basal region of the left ventricle was the area most affected.

In the dissection of the coronary arteries of Case 9 a piece of calcium was noted to be lodged just proximal to the bifurcation of each of two small vessels (approximately $1.5 \mathrm{~mm}$. in diameter). Microscopic examination of these pieces of calcium (Fig. 6) revealed that they were similar in appearance to the deposits on the aortic valve and it is believed that these are calcareous emboli that originated from this valve. In the microscopic examination of blocks of myocardium from this case a third calcareous embolus was noted to be lodged in the lumen of an arteriole. In Case 12 one such embolus was found just proximal to the bifurcation of an artery $2 \mathrm{~mm}$. in diameter. It was not determined whether these emboli had caused any myocardial scarring or not. In none of the other cases of aortic stenosis were emboli found.

The results of necropsy in all patients with aortic and mitral stenosis at Hammersmith Hospital 


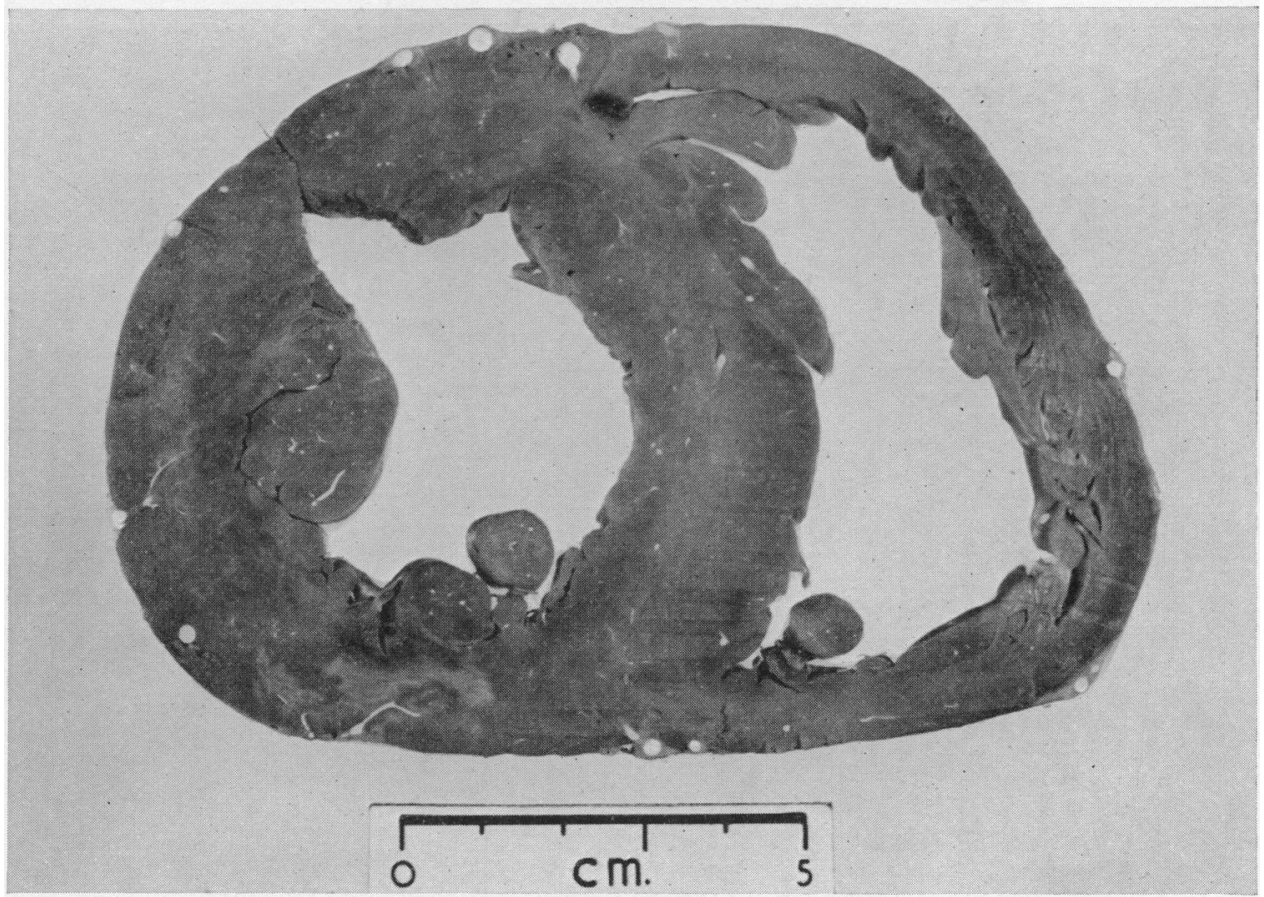

FIG. 4.-Aortic stenosis (Case 8), showing a slice of myocardium two-thirds of the way between apex and base. There is the scar of an old myocardial infarct in the posterior wall of the left ventricle, and in the outer one-quarter of the lateral wall are seen dark streaks of necrotic muscle. Note that the scar in the posterior wall does not involve the subendocardial region.

from 1948 to 1955 were reviewed for comparison with the present series. Of 88 cases of mitral stenosis only 4 had macroscopic myocardial fibrosis and reportedly normal coronary arteries. Two of these had old posterior myocardial infarcts and were subjected to special examination, while the other two cases had numerous foci of fibrosis in the posterior wall of the left ventricle. In one of the latter cases some of the foci of fibrosis were of recent origin. All four had severe mitral stenosis, overweight hearts, and long histories of congestive cardiac failure.

Of 63 cases of aortic stenosis 14 had macroscopic myocardial fibrosis and normal coronary arteries. The fibrosis in this group was described as being diffuse and patchy in seven cases, old postero-basal infarcts in two, a few fibrous flecks in two, patchy fibrosis in the postero-basal region in two, and a recent miliary infarct in one. Of these fourteen patients, seven had severe aortic stenosis, five had moderate aortic stenosis (one with aortic insufficiency), and two had mild aortic stenosis (one with aortic insufficiency). All had overweight hearts, only three weighing less than $500 \mathrm{~g}$. Congestive cardiac failure had occurred in 13 of the 14 patients.

Although the necropsies of these hearts were necessarily less extensive, the findings agreed essentially with the present study. In aortic stenosis with normal coronary arteries, myocardial fibrosis occurred when the hearts were enlarged and the degree of stenosis was moderate or severe. Myocardial fibrosis was much less frequent in mitral stenosis with normal coronary arteries and in all of the four instances in which it occurred it was situated in the posterior wall of the left ventricle and the degree of mitral stenosis was severe.

\section{Discussion}

Of the cases of mitral stenosis from the post-mortem series two had old posterior myocardial infarcts and one had numerous old and recent foci of fibrosis in the presence of normal coronary 


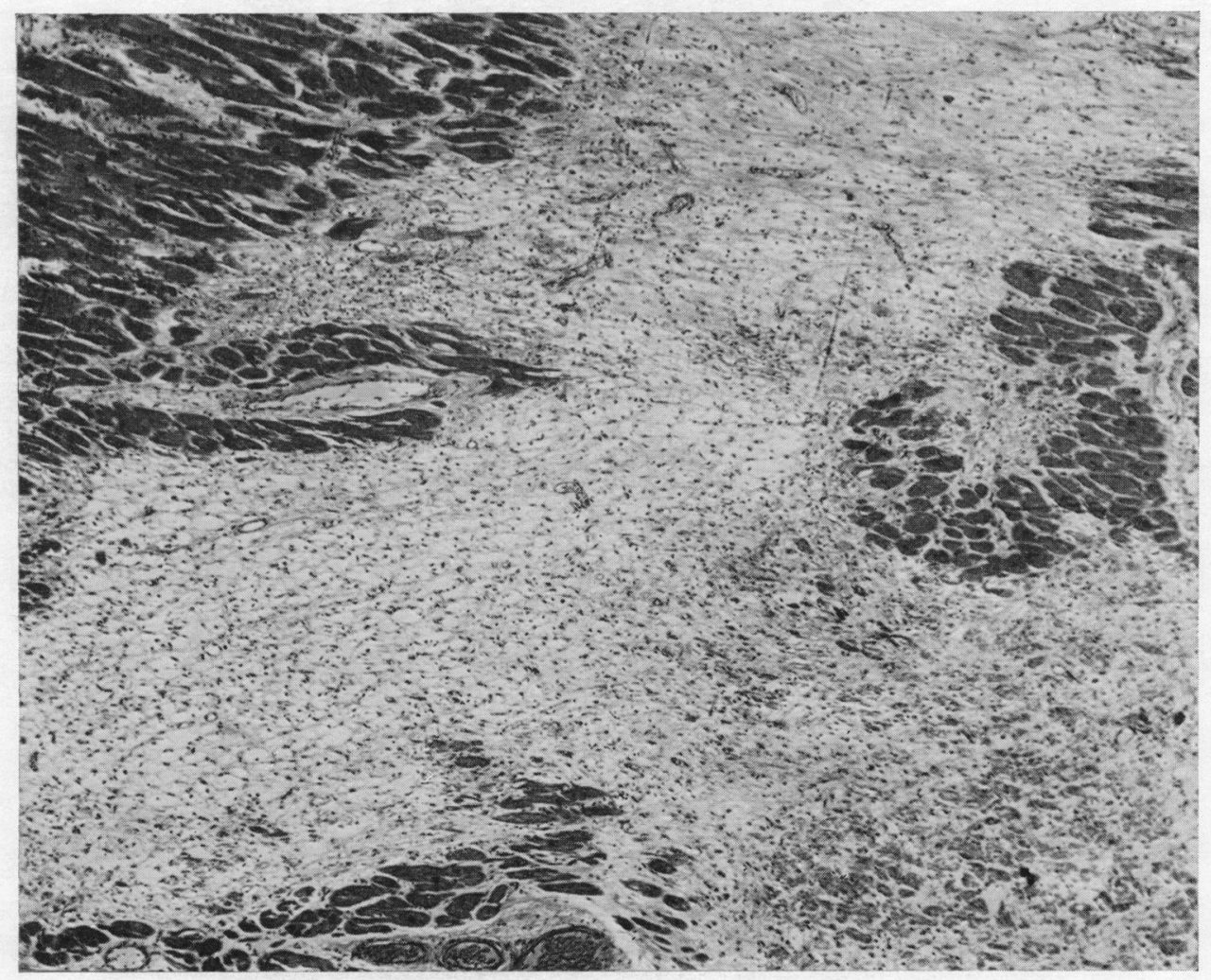

FIG. 5.-Aortic stenosis (Case 8), showing an area of recent ischæmic necrosis of muscle. In the lower right corner are seen necrotic muscle fibres, in the centre the necrotic fibres have disappeared leaving intact stroma, in the upper right corner fibrosis is occurring. Note injection mass in arteries. $(\times 50)$.

arteries. These myocardial lesions could not be considered due to coronary artery disease, nor by their nature, could they be considered due to rheumatic myocarditis; nor could the myocardial infarct in Case 7 due to either of these causes. Of the hearts on the present series with small focal fibrous scars, only in Case 4 were these scars larger than $2 \mathrm{~mm}$. in maximum dimension. In every instance there was either severe mitral stenosis or mitral stenosis plus regurgitation. Wood has drawn attention to the fact that angina pectoris in cases of mitral stenosis is more likely to occur when the degree of stenosis is severe or when there is in addition mitral regurgitation. He believes that the cardiac pain in these cases is due to myocardial ischæmia resulting from functional coronary insufficiency which in turn is related to a relatively fixed cardiac output. It is believed that the above-listed myocardial lesions are of the same causation. The lesions were almost entirely in the posterior wall of the left ventricle and Stuckey found that the electrocardiographic changes on exercise in the cases of mitral stenosis he studied, were greatest in the posterior leads (II, III and VF).

The small focal fibrous scars in Cases 2, 6, and 7 could also have been due to ischæmia or possibly to rheumatic myocarditis. Klinge (1930) found that "small white nodules" occurred in the myocardium of patients suffering recurrent attacks of rheumatic fever. He did not state the size of these nodules or how numerous they were, nor did he state whether they could occur following one attack of rheumatic fever. None of our seven cases were known to have had more than one attack of rheumatic fever. The aetiology of these small focal fibrous scars cannot be established 


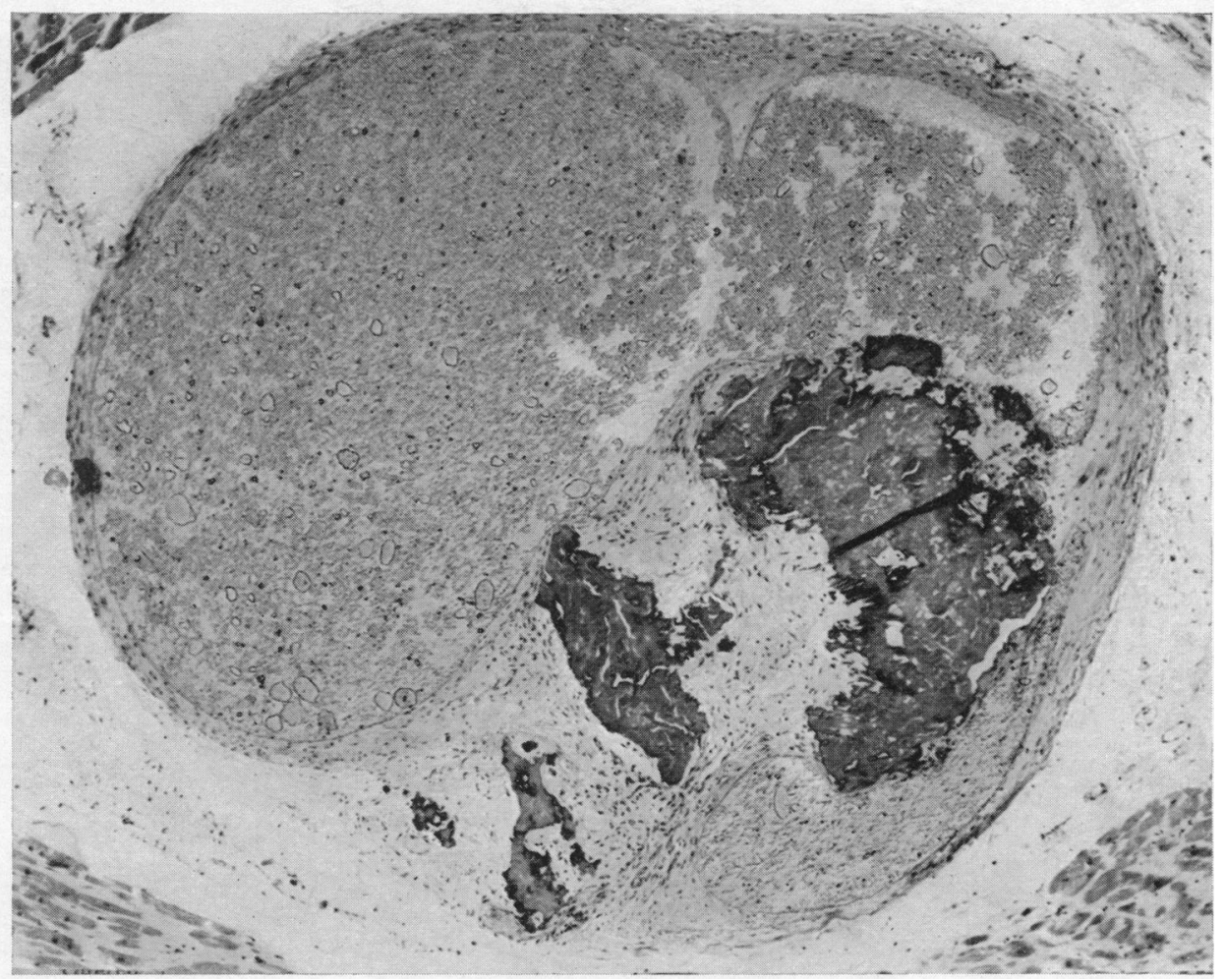

FIG. 6.-Aortic stenosis (Case 9), showing calcareous embolus lodged just proximal to the bifurcation of a small artery. There is destruction of the vessel wall in the lower portion of the photograph where the embolus is firmly attached by fibrous tissue. The rest of the vessel lumen is filled by barium.

with certainty, but it is evident from the seven cases of mitral stenosis that rheumatic myocarditis caused minimal, if any, macroscopically visible myocardial fibrosis.

Of the five cases of aortic stenosis with normal coronary lumina conspicuous myocardial fibrosis was found only in the three with severe aortic stenosis and grossly overweight hearts. This fibrosis could not be due to coronary artery disease, nor to rheumatic myocarditis since it was far in excess of the amount that may have been caused by this in cases with mitral stenosis. Similarly, since the size of the coronary arteries increased in proportion to the degree of cardiac enlargement, these areas of fibrosis cannot be considered due to myocardial ischæmia as a result of the myocardium outgrowing its blood supply. However, in hypertrophied, as in normal, hearts there is only one capillary per muscle fibre (Wearn, 1941). Since each muscle fibre is hypertrophied while each capillary remains of normal size (Payling Wright, 1954), enlarged hearts must be susceptible to ischæmia. There is no evidence that this factor alone causes myocardial fibrosis, at least not in hearts hypertrophied owing to hypertension (Harrison and Wood). By elimination, it is concluded that this fibrosis must be due to myocardial ischæmia as a result of functional coronary insufficiency. An area of recent muscle necrosis in the presence of normal coronary lumina in Case 8 supports this view. Friedberg and Horn (1939) have reported the occurrence of ischæmic muscle necrosis in the absence of coronary occlusion in cases of aortic stenosis, but all their patients had a significant degree of coronary artery disease.

Presumably, as with mitral stenosis, the fixed cardiac output in aortic stenosis plays a part in causing functional coronary insufficiency. The higher degree of myocardial fibrosis in the latter cases suggests that there must be additional factors. In experimental aortic stenosis, Green (1936) 
and Green and Gregg (1940) found a decreased systolic (and minute) coronary blood flow and suggested that this was due to increased myocardial compression of the coronary vessels with resultant increased systolic peripheral coronary resistance in relation to the aortic systolic pressure. Also, Gorlin et al. (1955) have shown that the left ventricular stroke work in severe aortic stenosis was increased two to four times. Either or both of these factors, plus the left ventricular hypertrophy present, would render these patients more susceptible to myocardial ischæmia. However, the numerous areas of fibrosis in Case 11 with a heart of normal weight perhaps indicates that functional coronary insufficiency may exist in aortic stenosis in the absence of left ventricular hypertrophy. When aortic insufficiency is present in addition to aortic stenosis the degree of stenosis need not be so severe before a fixed cardiac output results (Gorlin et al.). This perhaps explains why in Case 12 much myocardial fibrosis was present in spite of only moderate aortic stenosis and relatively mild coronary artery disease.

The areas of ischæmic necrosis in the eight cases of aortic stenosis reported by Friedberg and Horn were mainly situated in the subendocardial region of the anterior wall of the left ventricle. The myocardial fibrosis in congenital aortic stenosis reported by Marquis and Long was also in the subendocardial region of the left ventricle. In the present study of aortic stenosis the fibrosis was greatest in the deep parts of the left ventricular wall and mainly posteriorly. Possibly these fibrous scars represent infarcts of muscle bundles. In aortic stenosis tremendous strain falls upon the deep bulbo-spiral muscle bundle which would thus be more susceptible to myocardial ischæmia.

The finding of Kumpe and Bean (1948), and Lewes (1951), that cardiac pain was an index of the severity of the aortic stenosis, agrees with this study in that, although no case suffered from angina (except Case 14 when severely anæmic), the degree of myocardial fibrosis was roughly proportional to the degree of valvular stenosis. The degree of myocardial fibrosis in aortic stenosis was far in excess of that found in mitral stenosis. This is in agreement with the incidence of angina pectoris in the two groups. Wood noted anginal pain in 8 per cent of cases of mitral stenosis, whereas in aortic stenosis Kumpe and Bean noted it in 37 per cent, and Horan and Barnes (1948) in 28 per cent.

Although congestive cardiac failure might accentuate the functional coronary insufficiency in either mitral or aortic stenosis, it is not considered to be an essential cause of the ischæmic myocardial lesions in either group.

Cases 9 and 12 are of considerable interest because of the calcareous emboli that were shed from the aortic valves into the coronary arteries. In heavily calcified valves the most superficial portion of the calcareous material is sometimes seen to be rather loosely attached and friable either in the sinuses of Valsalva or on the ventricular surface of the valve. Perhaps the most obvious way for calcareous coronary emboli to arise from a diseased aortic valve would be for them to be swept into the coronary arteries from the calcium in the sinuses of Valsalva during diastole. However, in Cases 9 and 12 examination revealed only well attached calcareous material in this area. On the ventricular surfaces of the valves, however, there were masses of calcium of which the most superficial portions were loosely attached; it is believed that the calcareous fragments were broken off from the undersurface of the valves during systole, when this area would have been subjected to a high intraventricular pressure and increased rate of blood flow past the stenosed orifices. During diastole, especially when aortic regurgitation is also present, as it was in each instance, the emboli could be carried back in the regurgitant flow into the coronary orifices. That such emboli could cause myocardial ischæmia seems evident, but whether their number or size is significant is as yet undetermined.

Of further interest is the calcareous embolus to the right coronary artery in Case 5 following valvotomy on a heavily calcified mitral valve. In reviewing the data at necropsy, one other instance was found where a piece of calcium had lodged in the coronary artery following valvotomy on a calcified mitral valve. Although in neither patient did the embolus have any significant effect on the myocardium supplied by the vessel in which it lodged, it is possible that myocardial infarction could be a consequence. 
Knowing that calcareous emboli can occur from a calcified aortic valve spontaneously and from a calcified mitral valve following valvotomy, the probability that they occur following aortic valvotomy seems evident. One would expect them to be numerous following aortic valvotomy because this valve is usually heavily calcified; also one would expect coronary emboli to be especially frequent because of the proximity of this valve to the coronary orifices.

\section{SUMMARY AND CONCLUSIONS}

A coronary artery injection technique combined with a careful examination of the myocardium was used to study the hearts of seven cases of aortic stenosis and seven cases of mitral stenosis. An attempt was made to assess the amount of myocardial fibrosis that could not be considered due to coronary artery disease or to rheumatic myocarditis but therefore presumably due to functional coronary insufficiency. In addition the findings at necropsy in 88 patients with mitral stenosis and 63 with aortic stenosis were reviewed.

In aortic stenosis the amount of myocardial fibrosis occurring as a result of functional coronary insufficiency is related to the degree of stenosis of the aortic valve and the degree of left ventricular hypertrophy. When both of these are severe the fibrosis may be extensive.

Myocardial fibrosis as a result of functional coronary insufficiency may also develop in severe mitral stenosis, or in mitral stenosis and insufficiency, but it is much less common and much less extensive than in aortic stenosis. The fibrosis associated with mitral disease was almost entirely in the posterior wall of the left ventricle.

There was no evidence to suggest that rheumatic myocarditis causes any significant degree of macroscopically visible myocardial fibrosis.

Calcareous emboli may arise spontaneously from a heavily calcified aortic valve, and also from a heavily calcified mitral valve following valvotomy. Attention is drawn to the probability that such emboli would occur following aortic valvotomy.

I am very grateful to Professor C. V. Harrison, at whose suggestion this study was undertaken, for his advice, criticism, and encouragement. To him and to Dr. I. Doniach I am indebted for their help in the preparation of this paper. My thanks are also due to Dr. S. Daftary for the radiographs, to Mr. J. Griffin and the histology staff of the Postgraduate Medical School, to Miss R. Klein for the photographs, and to Mr. F. G. Saunders for Fig. 1.

\section{REFERENCES}

Brock, R. C. (1952). Brit. Heart J., 14, 489.

Dry, T. J., and Willius, F. A. (1939). Amer. Heart J., 17, 138.

Friedberg, C. K. (1949). Diseases of the Heart. Saunders and Co., London.

Gorlin, R., McMillan, I. K. R., Medd, W. E., Matthews, M. B., and Daley, R. (1955) Amer. J Med., $18,855$.

Green, H. D. (1936). Amer. J. Physiol., 115, 94.

, and Greeg, D. E. (1940). Amer. J. Physiol., 130, 126.

Harrison, C. V., and Wood, P. (1949). Brit. Heart J., 11, 205.

Horan, M. J., and Barnes, A. R. (1948). Amer. J. med. Sci., 215, 451.

Klinge, F. (1930). Virch. Arch., 279, 16.

Kumpe, C. W., and Bean, W. B. (1948). Medicine, 27, 139.

Lewes, D. (1951). Brit. med. J., 1, 211.

Marquis, R. M., and Long, A. (1955). Brit. Heart J., 17, 373.

Payling Wright, G. (1954). Introduction to Pathology. Longmans, London.

Stewart, J. D., Birchwood, E., and Wells, J. H. (1935). J. Amer. med. Ass., 104, 730.

Stuckey, D. (1955). Brit. Heart J., 17, 397.

Wearn, J. T. (1941). Bull. Johns Hopk. Hosp., 68, 363.

Wood, P. (1954). Brit. med. J., 1, 1051 and 1113. 